\title{
Could Bladder Inflation Prior to Cesarean Section Prevent Urinary Tract Injury in High Risk Group? A Randomized Controlled Trial
}

\author{
Abd El-Naser Abd El-Gaber Ali ${ }^{*}$, Mohammad A. M. Ahmed1', Mustafa M. Khodry', \\ Ahmed M. Abbas ${ }^{2}$ \\ ${ }^{1}$ Department of Obstetrics \& Gynecology, Faculty of Medicine, South Valley University, Qena, Egypt \\ ${ }^{2}$ Department of Obstetrics \& Gynecology, Faculty of Medicine, Assiut University, Asyut, Egypt \\ Email: *abdelnaser.abdelgaber@med.svu.edu.eg
}

How to cite this paper: Abd El-Gaber Ali, A.E.-N., Ahmed, M.A.M., Khodry, M.M. and Abbas, A.M. (2019) Could Bladder Inflation Prior to Cesarean Section Prevent Urinary Tract Injury in High Risk Group? A Randomized Controlled Trial. Open Journal of Obstetrics and Gynecology, 9, 207-215.

https://doi.org/10.4236/ojog.2019.92021

Received: January 16, 2019

Accepted: February 12, 2019

Published: February 15, 2019

Copyright $\odot 2019$ by author(s) and Scientific Research Publishing Inc. This work is licensed under the Creative Commons Attribution International License (CC BY 4.0).

http://creativecommons.org/licenses/by/4.0/

\section{(c) (i) Open Access}

\begin{abstract}
Background: Accidental urinary tract particularly bladder injury during cesarean delivery has a significant maternal morbidity, as it may lead to extended operative time, infection of urinary tract and sometimes development of urinary tract fistulae. Objective: To find out the efficacy of urinary bladder inflation immediately prior to cesarean section (CS) procedure in minimizing incidence of accidently urinary tract injury in high risk patients. Setting: Obstetrics and Gynecology Department, Faculty of Medicine, South Valley University, Qena, Egypt. Duration: From August 2017 to November 2018. Study Design: A prospective randomized controlled trial. Methods: Seventy six pregnant women recruited from attendants of outpatient antenatal care unit of obstetrics and gynecology department who planned for cesarean delivery and carried one or more risk factors for urinary tract injury. Patients randomly were classified into 2 groups (group I included 38 cases, underwent bladder inflation using triple way Foley's catheter immediately before CS and group II included 38 cases, and underwent bladder deflation with 2 ways Foley's catheter immediately before CS. Results: The overall incidence of urinary tract injury was significantly higher in group II ( 7 cases $=18.4 \%)$ than in group I ( 2 cases $=5.2 \%)$ with $\mathrm{p}$ value $<0.001$. The incidence of urinary bladder injury was moderately significantly higher in group II ( 5 cases $=13.1 \%$ ) than group I ( 2 cases $=5.2 \%$ ) with $\mathrm{p}$ value $<0.01$; ureteric or combined vesico-ureteric injuries had been reported only in group II ( 1 case $=2.6 \%$ and 1 case $=2.6 \%)$ respectively with no case reported in group I $(\mathrm{p}<0.001)$. There was a highly statistically significant difference between group I and group II as regard to hospital stay $(\mathrm{p}<0.001)$ but mildly significant differences in operative time and remote urinary tract fistulae $(p<0.05)$. Conclusions:
\end{abstract}


There was significant reduction in urinary bladder injury, ureteric injury, operative time and hospital stay. Urinary bladder inflation immediately before cesarean section should be applied in patients who have any risk factor of dense bladder adhesion as a protective procedure against urinary tract injuries.

\section{Keywords}

Bladder Inflation, Urinary Tract Injury (UTI), Cesarean Section (CS)

\section{Introduction}

Urinary bladder injury is one of the operative morbidities of cesarean section. It occurs in $0.08 \%-0.94 \%$ of cesarean sections [1]. Repeated cesarean section and any type of morbidly adherent placenta (MAP) are considered the major risk factors for urinary tract injuries during cesarean delivery [2].

Pregnant women with previous cesarean delivery having chance of bladder injury during next cesarean section increase 3 -folds ( $0.6 \%$ repeat cesarean versus $0.19 \%$ primary cesarean section) [3]. In another study [4] reported that, patients with repeated Cesarean sections were associated with bladder injury in $0.81 \%$ of cases while bladder injury was reported only in $0.27 \%$ of patients who had Cesarean section for first time. Urinary bladder injury complicates about $11.7 \%$ of cesarean sections in women with placenta accreta spectrum (PAS) [5]. Urinary bladder adhesions are the main risk factor for urinary bladder injury. The incidence of urinary bladder adhesions increases with each subsequent cesarean section [6]. The insertion of Foley's catheter before cesarean section is a common practice; however, the benefits of bladder emptying by Foley's catheter during cesarean section are speculative rather than evidence based.

One of the expected values of use of Foley's catheter is to deflate the bladder, which may prevent bladder injury at time of entry and allow retraction of the bladder after its separation by its dissection from the lower uterine segment. However, in many studies literature had found that cesarean section without bladder deflation is safe [7] [8] [9] [10]. Non-use of indwelling Foley's catheter will allow spontaneous bladder filling during the time of the surgery. By extrapolation, the intentional bladder filling may be perceived as safe as spontaneous filling. This extrapolation is tested in a clinical trial. The presence of tough adhesions between the bladder and the lower uterine segment carries the risk of urinary bladder injury. Trial of separation of the bladder in such circumstances may result in bladder injury. Filling of the bladder will delineate the contour of the bladder and clarify the proper plane of dissection [6].

\section{Aim of Work}

The aim of this study was to find out the efficacy of urinary bladder inflation immediately prior to Cs procedure in minimizing incidence of accidently urinary tract injury in high risk patients. 


\section{Patients and Methods}

Seventy six pregnant women recruited from attendants of outpatient antenatal care unit of obstetrics and gynecology department, faculty of medicine, south valley university, Egypt and planned for elective cesarean section and carried one or more risk factors of urinary tract injury through duration began from $1^{\text {st }}$ of August 2017 to the end of November 2018.

Inclusion criteria, 1) maternal age 20 - 45 years old; 2) BMI $<35 \mathrm{~kg} / \mathrm{m}^{2}$; 3) singleton pregnancy; 4) presence of any risk factor of urinary bladder injury as (more than previous $3 \mathrm{CS}$, previous myomectomy, previous hysterectomy, current placenta previa and or any type of placenta accreta, history of previous bladder injury, previous ovarian or tubal surgeries, history of puerperal sepsis, history of PID, pelvic endometriosis, previous bladder surgeries as open bladder stone extraction or previous abdominal approach for repair of vesico-vaginal fistula). Exclusion criteria: 1) chronic medical disorders as cardiac, renal or hepatic diseases; 2) preterm labor; 3) multiple pregnancies; 4) presence of uterine pathology as fibroid uterus; 5) presence of ovarian cysts or masses.

The research was approved by the Committee of Ethics for Biomedical Researches, South Valley University at June 2017. All cases had been informed written consents before they be included in this study.

\subsection{Methodology}

Detailed full history taken, general, obstetric examination, full routine laboratory investigations were done. Obstetric ultrasound examination had been applied for all cases to confirm fetal biometrics, viability, fetal presentation placenta location and its maturity, amniotic fluid amount and turbidity and exclusion of multiple pregnancies, lower uterine segment assessment for scar thickness. Patients randomly (by using closed envelops) had been classified into 2 groups (group I included 38 cases who had inflated urinary bladder using triple way Foley's catheter immediately before CS and group II included 38 cases who had deflated urinary bladder with 2 ways Foley's catheter immediately before CS).

\subsection{Intervention}

All cesarean sections in both groups had been done by fixed one surgeon supported by fixed assistant team in the same hospital. Spinal or general anesthesia was used according to patient fitness as recommended by anesthesia team. Cesarean sections were done via pfannenstiel incision of anterior abdominal wall. In group I, triple-way Foley's catheter had been inserted before surgery after induction of anesthesia (general anesthesia for all cases in both groups). The catheter is connected freely to a urinary bag.

Evaluation of the drained urine was done (includes: amount, color, and character). Instillation of $200 \mathrm{ml}$ sterile saline was done by a $50 \mathrm{ml}$ syringe through the catheter irrigation way, and then irrigation way was closed temporarily by artery forceps. The draining tube of the drainage urinary bag was clamped until 
the end of the dissection or bladder from anterior uterine wall. After laparotomy the bladder in some cases was deflated by $50 \mathrm{ml}$ or further inflated by $50 \mathrm{ml}$ if needed to allow comfortable dissection. In group II the 2 ways Foley's catheter was used for evacuation of bladder and keeping it empty during the whole cesarean procedure. After opening of the parietal peritoneum of anterior abdominal wall, the surgeon had to assess the accessibility to the lower uterine segment. The diagnosis of urinary bladder adhesions was based only on the intraoperative assessment; actually there is no universal scoring system for adhesions between the uterus and the bladder in women who had previous CS [11]. For the purpose of this study, we had adopted the scoring system that reported by Bristlow and Montz [12]. Adhesions are described as avascular adhesions, vascular adhesions, or thick adhesions.

The catheter in both groups were removed 12 hours after CS except in cases of urinary bladder injuries where the Foley's catheter was replaced with a silicon catheter and retained for 14 days with continuous meticulous follow up. Patients in both groups were under regular follow for the next 3 months for remote postoperative urinary complications.

\subsection{The Outcome Measures}

Primary outcome: was to assess the incidence of intraoperative accidental bladder or ureteric injury. Secondary outcomes; was to assess the operative time, amount of blood loss during surgery, post-operative voiding dysfunction, hospital stay and postoperative remote urinary tract complications as urinary bladder or ureteric fistulae.

\section{Statistical Analysis}

SPSS version 22 (IBM Corp., Armonk, NY, USA) was used for statistical analysis. Quantitative data was expressed as mean \pm standard deviation (SD) while qualitative data was expressed as (frequency and percentage). Student $t$ test was used to compare means and Chi square to compare categorical data. $P$ values < 0.05 were used for statistical significance.

\section{Results}

There was no statistically significant difference between group I and group II as regard to maternal age, body mass index, parity, gestational age or in the previous risk factors of bladder adhesions with $\mathrm{p}>0.05$ (Table 1 ).

As regard to the incidence and types of intraoperative bladder adhesions, there was no statistically significant difference between both groups with $\mathrm{p}>$ 0.05 (Table 2).

The overall incidence of urinary tract injury was significantly higher in group II $(7$ cases $=18.4 \%)$ than in group I $(2$ cases $=5.2 \%)$ with $\mathrm{p}$ value $<0.001$. The incidence of urinary bladder injury was moderately significantly higher in group II $(5$ cases $=13.1 \%)$ than group I $(2$ cases $=5.2 \%)$ with $\mathrm{p}$ value $<0.01$, ureteric or 
combined vesico-ureteric injuries had been reported only in group II ( 1 case $=$ $2.6 \%$ and 1 case $=2.6 \%)$ respectively with no case reported in group $\mathrm{I}(\mathrm{p}<0.001)$ (Table 3).

There was a highly statistically significant difference between both groups in hospital stay (less in group I) with $\mathrm{p}<0.001$. There was no statistically significant difference between group I and group II as regard to operative blood loss, number of cases needed blood transfusion, the number of transfused blood units, or postoperative voiding dysfunction with $\mathrm{p}>0.05$, but there were mildly significant differences in operative time (was shorter in group I) and remote urinary tract fistulae with $\mathrm{p}<0.05$ (Table 4).

Table 1. The baseline characteristics of the study groups.

\begin{tabular}{cccc}
\hline Characteristics & Group I & Group II & P-value \\
$(\mathbf{N}=38)$ & $(\mathrm{N}=38)$ & $>0.05$ \\
Age, years (mean $\pm \mathrm{SD})$ & $34.8 \pm 2.4$ & $35.2 \pm 2.6$ & $>0.05$ \\
BMI, Kg/m $/ \mathrm{m}^{2}($ mean $\pm \mathrm{SD})$ & $28.5 \pm 1.4$ & $28.3 \pm 1.6$ & $>0.05$ \\
Parity (mean $\pm \mathrm{SD})$ & $4.2 \pm 0.2$ & $4.3 \pm 0.2$ & $>0.05$ \\
Gestational age, weeks (mean $\pm \mathrm{SD})$ & $37.0 \pm 2.2$ & $36.9 \pm 2.3$ & \\
Risk Factors of Urinary tract injury (mean $\pm \mathrm{SD})$ & & $3.6 \pm 0.5$ & $>0.05$ \\
Cesarean section number & $3.2 \pm 0.4$ & $2.2 \pm 0.7$ & $0.8 \pm 0.2$ \\
Placenta previa & $2.1 \pm 0.6$ & $3.2 \pm 1.3$ \\
Placenta accreta & $0.7 \pm 0.2$ & $0.7 \pm 0.2$
\end{tabular}

Table 2. Incidence and types of intraoperative bladder adhesions in study groups.

\begin{tabular}{cccc}
\hline & $\begin{array}{c}\text { Group I } \\
(\mathrm{N}=\mathbf{3 8})\end{array}$ & $\begin{array}{c}\text { Group II } \\
(\mathbf{N}=\mathbf{3 8})\end{array}$ & P value \\
\hline $\begin{array}{c}\text { Incidence of adhesions, } \mathrm{n}(\%) \\
\text { Types of adhesions, } \mathrm{n}(\%)\end{array}$ & $17(44.7)$ & $15(39.4)$ & $>0.05$ \\
Avascular adhesions & & $4(26.7)$ & $>0.05$ \\
Vascular adhesions & $4(23.5)$ & $6(40)$ & $>0.05$ \\
Dense adhesions & $7(41.1)$ & $5(33.3)$ & $>0.05$ \\
\hline
\end{tabular}

Table 3. Incidence and types of urinary tract injury in study groups.

\begin{tabular}{cccc}
\hline & $\begin{array}{c}\text { Group I } \\
(\mathrm{N}=38)\end{array}$ & $\begin{array}{c}\text { Group II } \\
(\mathbf{N}=38)\end{array}$ & P-value \\
\hline $\begin{array}{c}\text { Incidence of urinary tract injury, n (\%) } \\
\text { Types of injury, n (\%) }\end{array}$ & $2(5.2)$ & $7(18.4)$ & $<0.001$ \\
Urinary bladder injury & $2(5.2)$ & $5(13.1)$ & $<0.001$ \\
Ureteric injury & $0(0.0)$ & $1(2.6)$ & $<0.001$ \\
Combined Vesico-ureteric injury & $0(0.0)$ & $1(2.6)$ & $<0.001$ \\
\hline
\end{tabular}


Table 4. Comparison between study groups regarding the study outcomes.

\begin{tabular}{cccc}
\hline & $\begin{array}{c}\text { Group I } \\
(\mathbf{N}=\mathbf{3 8})\end{array}$ & $\begin{array}{c}\text { Group II } \\
(\mathbf{N}=\mathbf{3 8})\end{array}$ & P-value \\
\hline Operative time, minutes $($ mean $\pm \mathrm{SD})$ & $44.7 \pm 11.4$ & $63.5 \pm 13.2$ & $<0.05$ \\
Operative blood loss, $m l($ mean $\pm \mathrm{SD})$ & $454.9 \pm 89.6$ & $487 \pm 94.8$ & $>0.05$ \\
No of cases needed for blood transfusion $(\mathrm{n}, \%)$ & $2(5.2)$ & $3(7.9)$ & $>0.05$ \\
Number of blood units needed (mean $\pm \mathrm{SD})$ & $1.0 \pm 0.4$ & $1.2 \pm 0.6$ & $>0.05$ \\
$\quad$ Hospital Stay in days (mean $\pm \mathrm{SD})$ & $0.9 \pm 0.3$ & $1.6 \pm 0.8$ & $<0.001$ \\
Postoperative voiding dysfunction $(\mathrm{n}, \%)$ & $4(10.5)$ & $5(13.1)$ & $>0.05$ \\
$\quad$ Remote urinary fistula & $1(2.6)$ & $2(5.2)$ & $<0.05$ \\
\hline
\end{tabular}

\section{Discussion}

With global increase in cesarean deliveries rates, obstetricians have to be cognizant of the potential complications of this procedure. Fortunately CS usually associated with lower maternal morbidity and mortality rates over the latest century. Anyhow, the most common registered complication of pelvic surgery is urinary tract injury, especially urinary bladder injury during pelvic surgery particularly cesarean section [13]. Risk of urinary tract injuries increases to $1.5 \%$ after four or more previous uterine incisions [14].

Pelvic adhesions related to the urinary bladder that could be present during cesarean section procedure are most risk factors for bladder injury due to its distortion of normal anatomy, and make dissection of urinary bladder so difficult through these dense adhesions. Sometimes some surgeons use different techniques in cesarean section to minimize possibility of future development of adhesions, examples of these techniques that may reduce postoperative adhesions development: 1) maximal tissues respect during dissection and handling, 2) minimizing of blood loss, 3) always keep maintenance of the tissue moisture [15] [16].

Phipps et al. study had been considered as one of the largest studies that looked at urinary bladder injury during cesarean delivery, the study was conducted as a case control study of pregnant women undergoing cesarean section, and the study had reported 42 cases with bladder injuries among 14,757 cesarean deliveries (incidence about $0.28 \%$ ) [17]. In Phippes et al. study $60 \%$ of cases with urinary bladder injuries had a dense adhesions discovered at time of operation due to repeated cesarean sections versus the $10 \%$ of the controls. As regard to the traditional concept that immediately preoperative evacuation of bladder and maintained empty through the whole surgical time by 2 ways Foley's catheter could prevent or minimize the incidence of urinary bladder injury during cesarean section [18].

Our study aimed to clear this traditional concept that sometimes maintained full bladder or at least semi full bladder may minimize or prevent bladder injury during cesarean delivery particularly in women who carry risk factor of previous 
dense adhesions. In this study we had found no significant differences between group I and group II as regard to demographic data (maternal age, BMI, parity and gestational age) or in risk factors of increased urinary bladder injury, also this study found no statistically significant differences between both groups in the incidence or types of pelvic adhesions during operative procedure. In this study, we had found a lower incidence of urinary tract injuries in group I (patients with inflated urinary bladder just before cesarean section), this result was theoretically plausible and preliminary data from previous researches could support this finding, however, results of a randomized controlled trial reported by Ozcan et al. [6] that included 66 patients with placenta percreta did not found any beneficial effect of bladder filling on prevention of urinary tract injury, this because Ozcan et al. study had included only patients with placenta percreta and the incidence urinary bladder injury rate in placenta accreta usually $15 \%-43 \%$ and even higher in placenta percreta [19] [20], beside Ozcan et al. study included women who had hysterectomy, actually cesarean hysterectomy is associated with an increase in the urinary tract injury incidence rates [21] [22]. Finally, the management such cases which associated with placenta percreta is highly variable from institution to another with great impact of the skills of the operating surgery beside, massive bleeding may put surgeon in a great stress to overcome this marked blood loss in a timed manner that may endanger the urinary tract, anyhow in our study placenta percreta cases had been presented in a small figure in comparison to the other risk factor.

In this study the operative time and hospital stay were significantly shorter in group I than in group II with which was very pleasant for the patients in minimize the total cost and early return to their usual life and these results agreed with Ozcan et al. [6]. The difference in the operative blood loss between the two groups was insignificant, so urinary bladder inflation before starting surgery had no effect in minimize the need for blood transfusion in this study or in Ozcan et al. [6] while this maneuver had minimized incidence of blood transfusion that needed during or immediately postoperative as reported by Matsubara et al. [23]. Furthermore, the later state that the primary aims for the bladder inflation was to minimize the bleeding rather than to prevent the urinary bladder injury as this allowed easy cutting and ligation of the aberrant vessels. As regard to postoperative voiding dysfunction, the patients in both group had a non-significant difference with $\mathrm{p}>0.05$. Finally remote urinary tract complications as ureteric or urinary fistulae, group I reported one case $(2.6 \%)$ of postoperative urinary bladder fistula but in the other side group II reported two cases $(5.2 \%)$ developed remote urinary fistula with mildly statistically significance $(\mathrm{p}<0.05)$.

The small sample size was the main limitation of this study but anyhow further studies related to this work undergoing in our department for more and accurate results.

\section{Conclusions}

Urinary bladder inflated prior to cesarean section had the following: 
1) Significant reduction in urinary bladder and ureteric injuries.

2) Significant reduction in operative time and hospital stay.

3) Neutral as regard to postoperative voiding dysfunction.

4) Complete absence of remote postoperative urinary tract complications.

\section{Recommendations}

This study recommended filling of urinary bladder immediately before cesarean section and being maintained all over the time of bladder dissection should be applied in patients who have any risk factor of dense bladder adhesion as a protective procedure against urinary bladder injury.

\section{Conflicts of Interest}

The authors declare that they have no conflict of interest.

\section{References}

[1] Korniluk, A., Kosinski, P. and Wielgos, M. (2017) Intraoperative Damage to the Urinary Bladder during Cesarean Section-Literature Review. Ginekologia Polska, 88, 161-165. https://doi.org/10.5603/GP.a2017.0031

[2] Salman, L., Aharony, S., Shmueli, A., Wiznitzer, A., Chen, R. and Gabbay-Benziv, R. (2017) Urinary Bladder Injury during Cesarean Delivery: Maternal Outcome from a Contemporary Large Case Series. European Journal of Obstetrics, Gynecology, and Reproductive Biology, 213, 26-30. https://doi.org/10.1016/j.ejogrb.2017.04.007

[3] Sibai, B.M. and Newton, E.R. (2007) The Urinary Tract in Pregnancy. In: Walters, M.D. and Karram, M.M., Eds., Urogynecology and Reconstructive Pelvic Surgery, Mosby Elsevier, Philadelphia, 472-489. https://doi.org/10.1016/B978-0-323-02902-5.50043-5

[4] Rahman, M.S., Gasem, T., Al Suleiman, S.A., Al Jama, F.E., Burshaid, S., et al. (2009) Bladder Injuries during Cesarean Section in a University Hospital: A 25-Year Review. Archives of Gynecology and Obstetrics, 279, 349-352. https://doi.org/10.1007/s00404-008-0733-1

[5] Alanwar, A., Al-Sayed, H.M., Ibrahim, A.M., Elkotb, A.M., Abdelshafy, A., Abdelhadi, R., Abbas, A.M., Abdelmenam, H.S., Fares, T., Nossair, W. and Abdallah, A.A. (2017) Urinary Tract Injuries during Cesarean Section in Patients with Morbid Placental Adherence: Retrospective Cohort Study. The Journal of Maternal-Fetal \& Neonatal Medicine, 1, 1-7.

[6] Ozcan, H.C., Balat, O., Ugur, M.G., Sucu, S., Tepe, N.B. and Kazaz, T.G. (2018) Use of Bladder Filling to Prevent Urinary System Complications in the Management of Placenta Percreta: A Randomized Prospective Study. Geburtshilfe und Frauenheilkunde, 78, 173-178. https://doi.org/10.1055/s-0044-100039

[7] Pandey, D., Mehta, S., Grover, A. and Goel, N. (2015) Indwelling Catheterization in Caesarean Section: Time to Retire It! Journal of Clinical and Diagnostic Research, 9 , QC01-QC4. https://doi.org/10.7860/JCDR/2015/13495.6415

[8] Senanayake, H. (2005) Elective Cesarean Section without Urethral Catheterization. The Journal of Obstetrics and Gynaecology Research, 31, 32-37. https://doi.org/10.1111/j.1447-0756.2005.00237.x

[9] Acharya, S., Uprety, D.K., Pokharel, H.P., Amatya, R. and Rai, R. (2012) Cesarean Section without Urethral Catheterization: A Randomized Control Trial. Kathmandu 
University Medical Journal (KUM), 10, 18-22. https://doi.org/10.3126/kumj.v10i2.7337

[10] Abdel-Aleem, H., Aboelnasr, M.F., Jayousi, T.M. and Habib, F.A. (2014) Indwelling Bladder Catheterization as Part of Intraoperative and Postoperative Care for Caesarean Section. The Cochrane Database of Systematic Reviews, 4, CD010322.

[11] Poole, J.H. (2013) Adhesions Following Cesarean Delivery: A Review of Their Occurrence, Consequences and Preventative Management Using Adhesion Barriers. Women's Health (London, England), 9, 467-477. https://doi.org/10.2217/WHE.13.45

[12] Bristow, R.E. and Montz, F.J. (2005) Prevention of Adhesion Formation after Radical Oophorectomy Using a Sodium Hyaluronate-Carboxymethylcellulose (HA-CMC) Barrier. Gynecologic Oncology, 99, 301-308. https://doi.org/10.1016/j.ygyno.2005.06.057

[13] Mendez, L.E. (2001) Iatrogenic Injuries in Gynecologic Cancer Surgery. Surgical Clinics of North America, 81, 897-923. https://doi.org/10.1016/S0039-6109(05)70173-0

[14] Scotti, R.J., Young, J.N. and Ho, M.H. (2008) Urologic Complications. In: O’Grady, J.P., Gimovsky, M.L., Bayer-Zwirello, L. and Giordano, K., Eds., Operative Obstetrics, 2nd Edition, Cambridge University Press, Cambridge, 608-637. https://doi.org/10.1017/CBO9780511580987.021

[15] The Practice Committee of the American Society for Reproductive Medicine in collaboration with the Society of Reproductive Surgeons (2008) Pathogenesis, Consequences, and Control of Peritoneal Adhesions in Gynecologic Surgery. Fertility and Sterility, 90, S144-S149.

[16] Likakos, T., Thomakos, N., Fine, P.M., Dervenis, C. and Young, R.L. (2001) Peritoneal Adhesions: Etiology, Pathophysiology, and Clinical Significance: Recent Advances in Prevention and Management. Digestive Surgery, 18, 260-273. https://doi.org/10.1159/000050149

[17] Phipps, M.G., Watabe, B., Clemons, J.L., Weitzen, S. and Myers, D.L. (2005) Risk Factors for Bladder Injury during Cesarean Delivery. Obstetrics \& Gynecology, 105 156-160. https://doi.org/10.1097/01.AOG.0000149150.93552.78

[18] Arulkumaran, S., Cheng, H., Ingermarson, I., Low, H.S. and Ratnam, S.S. (1986) Is There a Need for Routine Indwelling Catheter after Caesarean Section? Singapore Medical Journal, 27, 54-57.

[19] Faranesh, R., Romano, S., Shalev, E. and Salim, R. (2007) Suggested Approach for Management of Placenta Percreta Invading the Urinary Bladder. Obstetrics and Gynecology, 110, 512-515. https://doi.org/10.1097/01.AOG.0000267135.31817.d6

[20] Silver, R.M., Fox, K.A., Barton, J.R., et al. (2015) Center of Excellence for Placenta Accreta. American Journal of Obstetrics and Gynecology, 212, 561-568. https://doi.org/10.1016/j.ajog.2014.11.018

[21] Wright, J.D., Devine, P., Shah, M., et al. (2010) Morbidity and Mortality of Peripartum Hysterectomy. Obstetrics and Gynecology, 115, 1187-1193. https://doi.org/10.1097/AOG.0b013e3181df94fb

[22] Baskett, T.F., Calder, A.A. and Arulkumaran, S. (2007) Obstetrics Hysterectomy. In: Munro Kerr's Operative Obstetrics, 11th Edition, Saunders Elsevier, Edinburgh, 309-314.

[23] Matsubara, S. (2018) "Filling the Bladder" at Cesarean Hysterectomy for Placenta Percreta. Geburtshilfe und Frauenheilkunde, 78, 715-716. https://doi.org/10.1055/a-0592-5032 